\title{
Characterization of the responses of the caspase 2, 3, 6 and 8 genes to immune challenges and extracellular ATP stimulation in the Japanese flounder (Paralichthys olivaceus)
}

\author{
Shuo Li, Jiafang Li, Weijiao Peng, Gaixiang Hao and Jinsheng Sun *io
}

\begin{abstract}
Background: Caspases are a family of conserved intracellular cysteine-dependent aspartate-specific cysteine proteases that play important roles in regulating cell death and inflammation. Our previous study revealed the importance of the inflammatory caspase 1 gene in extracellular ATP-mediated immune signaling in Japanese flounder, Paralichthys olivaceus. To explore the potential roles of other caspases in P. olivaceus innate immunity, we extended our study by characterizing of the responses of four additional $P$. olivaceus caspase genes, termed JfCaspase 2, 3, 6 and 8, to inflammatory challenge and extracellular ATP stimulation.

Results: Sequence analysis revealed that the domain structures of all the Japanese flounder caspase proteins are evolutionarily conserved. Quantitative real-time PCR analysis showed that the JfCaspase 2, 3, 6 and 8 genes were expressed ubiquitously but at unequal levels in all examined Japanese flounder normal tissues. In addition, the basal gene expression levels of JfCaspase 2, 3, 6 and 8 were higher than those of JfCaspase 1 in both Japanese flounder head kidney macrophages (HKMs) and peripheral blood leukocytes (PBLs). Furthermore, immune challenge experiments showed that the inflammatory stimuli LPS and poly(l:C) significantly modulated the expression of the JfCaspase 2, 3, 6 and 8 genes in Japanese flounder immune cells. Finally, DNA fragmentation, associated with increased extracellular ATP-induced JfCaspase 2, 3, 6 and 8 gene expression and enzymatic activity, was inhibited by the caspase inhibitor Z-VAD-FMK in the HKMs.
\end{abstract}

Conclusion: Our findings demonstrate broad participation of multiple caspase genes in response to inflammatory stimulation in Japanese flounder immune cells and provide new evidence for the involvement of caspase(s) in extracellular ATP-induced apoptosis in fish.

Keywords: Extracellular ATP, Caspases, Immune response, Apoptosis, Teleost, Paralichthys olivaceus

\footnotetext{
* Correspondence: skysjs@tjnu.edu.cn

Shuo Li is a senior author.

Tianjin Key Laboratory of Animal and Plant Resistance, College of Life

Sciences, Tianjin Normal University, 393 West Binshui Road, Tianjin 300387,

Xiqing District, China
}

(c) The Author(s). 2019 Open Access This article is distributed under the terms of the Creative Commons Attribution 4.0 International License (http://creativecommons.org/licenses/by/4.0/), which permits unrestricted use, distribution, and reproduction in any medium, provided you give appropriate credit to the original author(s) and the source, provide a link to the Creative Commons license, and indicate if changes were made. The Creative Commons Public Domain Dedication waiver (http://creativecommons.org/publicdomain/zero/1.0/) applies to the data made available in this article, unless otherwise stated. 


\section{Background}

Caspases are a family of conserved intracellular cysteinyl aspartate-specific proteases that trigger programmed cell death (apoptosis or pyroptosis) and inflammation to maintain homeostasis in organisms from worm to human beings [1-3]. The family of caspase proteins contains 14 members in mammals (caspases 1-3, 6-9, 12 and 14 in humans and mice; caspases 4, 5 and 10 in humans; and caspase 11 in mice). The major caspase proteins can be functionally classified into apoptotic caspases including the initiator caspases (caspases 2, 8, 9 and 10) and the effector/executioner caspases (caspases 3, 6 and 7), and the inflammatory caspases (caspases 1, 4, 5, 12 in humans and caspases 1,11 and 12 in mice).

Caspases are tightly controlled as inactive zymogens (also known as procaspases) and are activated following signaling events promoting their cleavage and aggregation into dimers or macromolecular complexes [1]. The initiator caspases, which are activated by intrinsic and/or extrinsic signals, can cleave and activate the effector caspases, which in turn cleave target proteins during apoptosis, while the inflammatory caspases are primarily involved in pro-inflammatory cytokine processing during inflammatory processes [4] and in the promotion of innate immune responses to various internal and external stimuli [1]. Interestingly, both the initiator and effector functions are found within the inflammatory pyroptotic caspases (caspases 1, 4, 5 and 11) [2].

To date, several caspase genes have been cloned, including caspase 1 from gilthead seabream, Sparus aurata [5]; caspases 1, 2, 3, and 9 from tongue sole, Cynoglossus semilaevis [6]; caspases 1, 2, 3, 8, 9 and 10 from striped murrel, Channa striatus $[7,8]$; caspases 3,8 and 9 from sea bass, Dicentrarchus labrax L. [9-11]; caspase 3 from rock bream, Oplegnathus fasciatus [12]; caspase 6 from rainbow trout, Oncorhynchus mykiss [13]; caspases 3 and 9 in large yellow croaker, Pseudosciaena crocea [14, 15]; and caspases 1 and 10 from Japanese flounder, Paralichthys olivaceus $[16,17]$. Previous studies have revealed the immunological significance of different caspases in fish. Upon overexpression of caspases in tongue sole, Long et al. found that caspase genes 1,2, 3 and 9 are essential to optimal defense against bacterial infection in fish [6]. Banerjee et al. reported that the caspase 3 protein mediated head kidney macrophage apoptosis during Aeromonas hydrophila infection in Clarias batrachus [18]. In addition, the involvement of the caspases 3 and 6 proteins in apoptotic cell death during red sea bream iridovirus infection has also been suggested [19].

Our previous studies revealed that extracellular ATP (eATP) is a potent signaling molecule in the activation of the innate immune responses in fish [20-22]. We recently identified and characterized a caspase 1 gene (namely, JfCaspase 1) in Japanese flounder, P. olivaceus, and showed that eATP can rapidly upregulate IfCaspase 1 gene expression and enhance its enzymatic activity in Japanese flounder immune cells, suggesting the involvement of caspases in eATP-mediated immune signaling in fish [17]. In this report, we identified and characterized the responses of four additional caspase genes, termed JfCaspases 2, 3, 6 and 8, to inflammatory stimulation in $P$. olivaceus immune cells. We also investigated the gene expression patterns and enzymatic activitiy induced by eATP stimuli. Our findings revealed that inflammatory stimuli, as well as the important danger-associated signaling molecule, eATP, have a broad effect on the gene expression of multiple caspase family members in Japanese flounder immune cells. In particular, we showed an association of eATP-induced DNA fragmentation with increased JfCaspase 2, 3, 6 and 8 gene expression and enzymatic activity in Japanese flounder immune cells. Our findings suggest that caspase(s) may play an important role in eATP-induced apoptosis in fish.

\section{Methods}

Fish maintenance and tissue sampling

The experimental fish $P$. olivaceus were obtained from a local fish farm in Tianjin, China. Fish were maintained in an aerated running sea water system in the laboratory for two weeks before experiments. Only healthy fish without any pathological signs were selected for experimentation. To collect tissue, fish were euthanized with $0.25 \mathrm{~g} / \mathrm{L}$ tricaine methanesulfonate (Sigma-Aldrich); blood were collected and tissues including the gill, head kidney, trunk kidney, heart, liver, skin, muscle, intestine and spleen were dissected from individual healthy Japanese flounder under sterilized conditions. Samples of the same kind of tissue from five individual fish were pooled, and total RNA was extracted (see below) to analyze the basal tissue expression of Japanese flounder caspase genes by quantitative real-time PCR (qRT-PCR).

\section{RNA extraction, CDNA preparation and gene cloning}

Total RNA from cells and tissues was extracted using a PureLink ${ }^{\circ}$ RNA Mini Kit and TRIzol reagent (Invitrogen), respectively, according to the manufacturer's instructions. The integrity of the purified total RNA was examined with a $1.5 \%$ formaldehyde denaturing agarose gel. Then, the RNA was quantified by a NanoDrop spectrophotometer and treated with DNase I (Invitrogen, amplification grade) to remove genomic DNA contaminations following the protocol specified by the supplier. First-strand cDNA was then synthesized using a SuperScript III reverse transcriptase kit (Invitrogen) according to the manufacturer's directions. The entire coding regions of the IfCaspase 2, 3, 6 and 8 cDNA were amplified from Japanese flounder spleen or liver tissue using Platinum ${ }^{\mathrm{Tt}}$ Taq DNA Polymerase (Invitrogen) with the primer pairs listed in Table 1, 
Table 1 Primers used in this study

\begin{tabular}{|c|c|c|}
\hline Primer name & Sequences $\left(5^{\prime} \rightarrow 3^{\prime}\right)$ & Applications \\
\hline JfCaspase 2-f & GGAGCAGCTGGACGATCGAC & Gene cloning \\
\hline JfCaspase 2-r & ATATGTGCATGTGATCGATA & \\
\hline JfCaspase 3-f & CAACAACAAGAACTTCGACAGG & \\
\hline JfCaspase 3-r & TGTATATGTCAGGACAGTGCAA & \\
\hline JfCaspase 6-f & CATTCGGAAGGAGAGAGGGA & \\
\hline JfCaspase 6-r & GTGCTCAGCAACGACATACAG & \\
\hline JfCaspase 8-f & CTGGCTTGTGTGGGAGGGAG & \\
\hline JfCaspase 8-r & CAGCAATCTGTATCATACAGG & \\
\hline qJfCaspase $2-f$ & CCTCGTGGTTTCGCCTTG & qRT-PCR \\
\hline qJfCaspase 2-r & CGGTGGTCTGGTCGTTGG & \\
\hline qufCaspase 3-f & TCGCTGCAAATCGCTGGT & \\
\hline qufCaspase 3-r & CTGTGGAGAAGGCGTAGAGGA & \\
\hline qufCaspase 6-f & CTGAGCCACGGTGAGAACG & \\
\hline qufCaspase 6-r & ATTGTCCACGGCATCGCA & \\
\hline qufCaspase 8-f & CAGAGCCCTTCACGAGCAA & \\
\hline qufCaspase 8-r & CAAGGCACCGTCTCACCAT & \\
\hline beta-actin-f & AGGTTCCGTTGTCCCG & \\
\hline beta-actin-r & TGGTTCCTCCAGATAGCAC & \\
\hline
\end{tabular}

$f$ and $r$ denote forward and reverse primer, respectively

which were designed based on the available Japanese flounder JfCaspase 2, 3, 6 and 8 cDNA sequences (GenBank accession numbers: XP_019948600.1, AFC60626.1, XP_019956800.1 and XP_019955218.1, respectively) in the GenBank database of the National Center for Biotechnology Information. The PCR products with the expected sizes were purified with a GeneJET Gel Extraction Kit (Thermo Fisher Scientific) and cloned into a pMD18-T vector (TaKaRa) for DNA sequencing.

\section{Sequence data analyses}

The obtained nucleotide and protein sequences were searched against the GenBank database using the BLAST program (http://www.ncbi.nlm.nih.gov/) to determine their sequence identities. The deduced amino acid sequences of the IfCaspase 2, 3, 6 and 8 genes were translated using the ExPASy Translation Tool (http:// www.expasy.org) and showed $100 \%$ sequence identity with their respective reference sequences in the NCBI database. Multiple sequence alignment was performed using the Clustal Omega program (https://www.ebi.ac.uk/Tools/msa/clustalo/). The protein domain structures were searched in the Conserved Domain Database (https://www.ncbi.nlm.nih.gov/cdd). The percentages of amino acid sequence identity were calculated by pair-wise alignments at the NCBI website with the default settings. A neighbor-joining phylogenetic tree was constructed based on the multiple sequence alignments using MEGA 5.0 software with the number of bootstrap trials set to 10,000 .

\section{Preparation and cell culture of Japanese flounder head kidney macrophages and peripheral blood leukocytes} The procedure for the preparation of Japanese flounder primary head kidney cells was described previously [23]. Peripheral blood was collected from the caudal vein of Japanese flounder (average $800 \pm 50 \mathrm{~g}$ ) with a $10 \mathrm{ml}$ heparinized syringe. The obtained primary head kidney cells and blood cells were then used to isolate the head kidney macrophages (HKMs) and peripheral blood leukocytes (PBLs), respectively, by discontinuous Percoll gradient centrifugation with a previously described protocol [24]. The viability of the isolated cells was examined by trypan blue exclusion assay. Then, the HKMs and PBLs were cultured in RPMI 1640 medium (Invitrogen) supplemented with 10\% FBS and 1\% penicillin-streptomycin liquid (Invitrogen) at $21^{\circ} \mathrm{C}$.

\section{Analysis of the basal expression levels of JfCaspase genes in Japanese flounder tissues and immune cells}

The relative basal gene expression levels of JfCaspase 2, 3, 6 and 8 in Japanese flounder normal tissues and immune cells were determined by qRT-PCR analysis. Briefly, Japanese flounder tissues, including blood, gill, head kidney, trunk kidney, heart, liver, skin, muscle, intestine and spleen, were collected from five healthy Japanese flounder (average weight $500 \pm 20$ g). Each kind of tissue was equally pooled to avoid individual variation, and the pooled samples were used for RNA purification. Total RNA was purified, digested with DNase I and transcribed into cDNA as previously described. The relative gene expression levels for the individual IfCaspase gene were determined by qRT-PCR (see below) with beta-actin serving as an internal reference gene.

\section{Immune challenge experiments}

In vitro immune challenge experiments in Japanese flounder HKMs and PBLs with the pathogen-associated molecular pattern molecules LPS and poly(I:C) were detailed in a previous study [25]. Briefly, overnight-cultured Japanese flounder HKMs and PBLs $\left(5 \times 10^{6}\right.$ cells/well $)$ were treated with $20 \mu \mathrm{g} / \mathrm{ml}$ LPS or poly(I:C) (final concentration, dissolved in cell culture medium, Sigma-Aldrich) for $4,8,12,24,36$ or $48 \mathrm{~h}$. Cells without PAMP treatment served as the controls. After treatment, total RNA was purified and transcribed into cDNA, and LPS- and poly(I:C)-induced changes in JfCaspase 2, 3, 6 and 8 gene expression were measured by qRT-PCR. 
Measurement of eATP-induced JfCaspase gene expression and enzymatic activity in Japanese flounder HKMs

To explore the responses of JfCaspase genes to eATP treatment, Japanese flounder HKMs $\left(5 \times 10^{6}\right.$ cells/well) were stimulated with $1 \mathrm{mM}$ ATP (dissolved in cell culture medium) for the indicated durations. eATP-induced JfCaspase 2, 3, 6 and 8 gene expression changes compared with the expression in the untreated controls were measured by qRT-PCR.

The eATP-induced JfCaspase 2, 3, 6 and 8 enzymatic activity in the HKMs was determined with their respective enzymatic activity assay kits (Beyotime Institute of Biotechnology, China), according to the manufacturer's directions. The eATP-induced enzymatic activity of the JfCaspase 2, 3, 6 and 8 proteins is presented as the change in their respective substrates (Ac-VDQQD-pNA, Ac-DEVD-pNA, Ac-VEID-pNA and Ac-IETD-pNA, respectively) into the yellow formazan product p-nitroaniline (pNA). Briefly, the HKMs were lysed on ice for $15 \mathrm{~min}$ followed by centrifugation at $15000 \mathrm{rpm}$ for $15 \mathrm{~min}$. The protein concentrations were determined with a Bradford protein assay kit (Pierce). The supernatant, containing equal amounts of total proteins $(83.7 \mu \mathrm{g})$, was incubated in a 96 -well plate with $30 \mu \mathrm{l}$ of the respective substrates at $37^{\circ} \mathrm{C}$ for $2 \mathrm{~h}$. The absorbance values of pNA released from the substrates in the clarified supernatant were measured at $405 \mathrm{~nm}$ $\left(\mathrm{OD}_{405}\right)$ by a Tecan Infinite ${ }^{\bullet}$ M200 PRO multimode microplate reader (Switzerland). Each reaction was performed in triplicate. The eATP-induced JfCaspase enzymatic activity is presented as the pNA levels, which were calculated from a standard curve. The basal JfCaspase enzymatic activity in the HKMs without ATP treatment did not show any significant differences during the experiments (data not shown).

\section{DNA fragmentation assay}

The Japanese flounder HKMs were treated with or without $1 \mathrm{mM}$ ATP for 12 or $24 \mathrm{~h}$ in the presence or absence of pan-caspase inhibitor Z-VAD-FMK (Beyotime). After treatment, genomic DNA from the HKM cells was purified using a genomic DNA extraction kit for marine animals (Tiangen Biotech Co. Ltd., China) and treated with RNase A (Invitrogen). The same amount of DNA was loaded onto a $2 \%$ agarose gel, and DNA fragments were visualized by electrophoresis and staining with ethidium bromide. Without ATP treatment, no DNA fragmentation was observed in the HKMs during the experiments (data not shown).

\section{Real-time PCR analysis}

The relative gene expression levels of the IfCaspase 2, 3, 6 and 8 under normal conditions and different challenge conditions were determined by quantitative real-time PCR (qRT-PCR) analysis. qRT-PCR was performed on an Applied Biosystems 7500 Fast Real-Time PCR System (Thermo Scientific) using an AceQ qPCR SYBR Green Master Mix kit (Vazyme Biotech Co. Ltd., China) according to the manufacturer's recommendations. The primers for the detection of the individual JfCaspase genes are listed in Table 1 . The amplification efficiencies of the primer pairs for qRT-PCR detection of the IfCaspase 2, 3, 6 and 8 genes were $99.39,99.14,103.14$ and $98.98 \%$, respectively, which were determined based on the slopes of standard curves constructed for each amplicon using serial dilutions of the respective plasmid as templates. Gene expression levels were evaluated using the comparative $2^{-\triangle \Delta C t}$ quantification method with beta-actin as an internal reference gene. Melting curve analysis and gel electrophoresis were performed at the end of amplification. The PCR products were further sequenced to ensure the specificity of amplification.

\section{Statistics}

All data are presented as the mean \pm standard deviation from triplicate experiments. The results were statistically analyzed with Student's $t$-test for comparison between two groups. A $p$ value less than 0.05 was considered statistically significant.

\section{Results and discussion}

\section{Sequence analysis of Japanese flounder caspase proteins}

The characteristics of the Japanese flounder caspase proteins are summarized in Table 2. JfCaspase 1 encodes a 384-amino-acid protein with a predicted molecular mass of $43.7 \mathrm{kDa}$. JfCaspase 2 encodes a 459 -amino-acid protein with a predicted molecular mass of $52.09 \mathrm{kDa}$. JfCaspase 3 encodes a 214-amino-acid protein with a predicted molecular mass of $23.92 \mathrm{kDa}$. IfCaspase 6 encodes a 299-amino-acid protein with a predicted molecular mass of $33.70 \mathrm{kDa}$. JfCaspase 8 encodes a 478 -amino-acid protein with a predicted molecular mass of $54.33 \mathrm{kDa}$. In addition, the JfCaspase 1, 2, 3 and 6 proteins have similar isoelectric points that are close to 6 , while JfCaspase 8 protein has a lower isoelectric point (Table 2).

Although the JfCaspase 1, 2, 3, 6 and 8 proteins exhibit different primary peptide sequences, they share a common caspase, interleukin-1 beta converting enzyme (ICE) homologues (CASc) domain containing a caspase active site pentapeptide (QACR/QG) motif (Fig. 1), a conservative feature of caspase-family proteins [26]. In addition, the JfCaspase 1 and 2 proteins contain an additional caspase recruitment domain (CARD), whereas JfCaspase 8 possesses two death effector domains (DED) required to signal apoptosis at the $\mathrm{N}$-terminus, allowing these three proteins to complex with different adapter proteins and trigger different downstream signaling pathways. Furthermore, the JfCaspase 3 protein has an ${ }^{84} \mathrm{RGD}^{86}$ motif that is involved in integrin recognition. These conserved 
Table 2 Characteristics of caspase proteins in Japanese flounder Paralichthys olivaceus

\begin{tabular}{lllllll}
\hline caspase & accession No. & $\mathrm{pl}$ & residues & Mw (kDa) & domain & predominant expression tissue \\
\hline 1 & ARI72010.1 & 5.87 & 384 & 43.76 & CARD,CASC & Skin [17] \\
2 & XP_019948600.1 & 6.06 & 459 & 52.09 & CARD, CASC & blood \\
3 & AFC60626.1 & 6.09 & 214 & 23.92 & CASC & skin, blood \\
6 & XP_019956800.1 & 5.86 & 299 & 33.70 & CASC & intestine \\
8 & XP_019955218.1 & 5.13 & 478 & 54.33 & DED, CASC & blood \\
10 & BAE98150.1 & 5.36 & 494 & 55.87 & DED, CASC & gills [16] \\
\hline
\end{tabular}

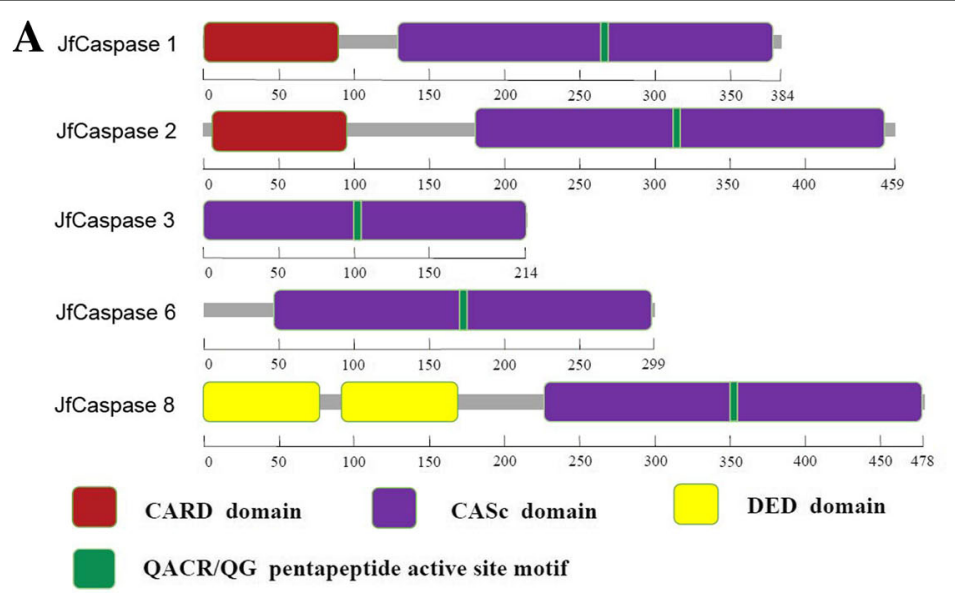

B

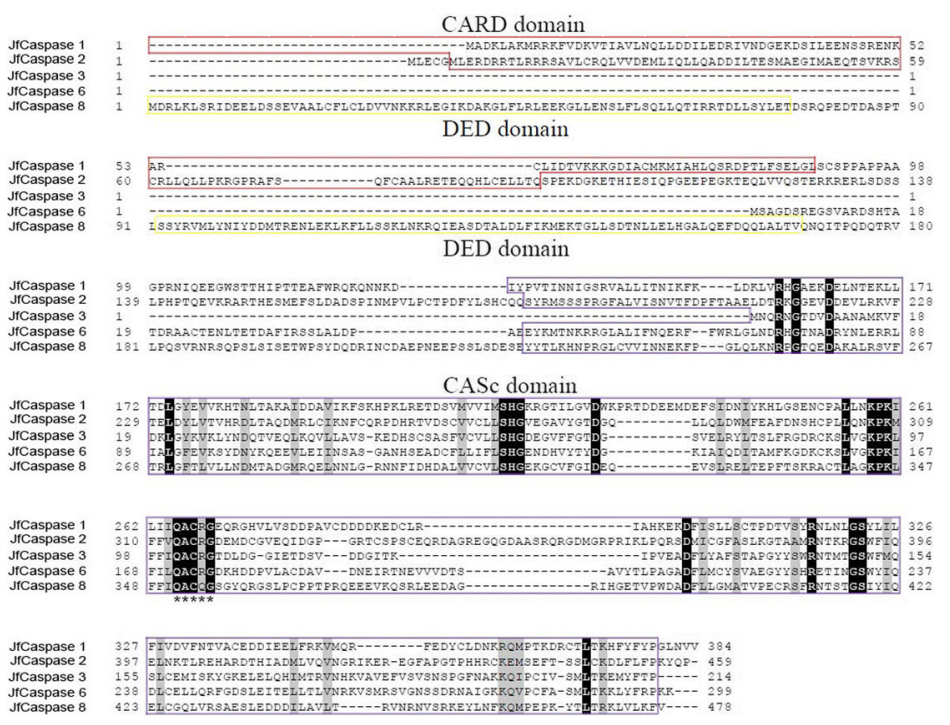

Fig. 1 Domain organization and sequence alignment of Japanese flounder caspase proteins. a Schematic protein domain architecture of Japanese flounder caspase proteins. CARD: caspase recruitment domain; DED: death effector domain; CASc: caspase, interleukin-1 beta converting enzyme (ICE) homologues. b Multiple alignment of the amino acid sequences of Japanese flounder caspase proteins. The CARD domain, DED domain and CASC domains are boxed in red, yellow and purple, respectively. The conserved QACR/QG pentapeptide active site motif in all the JfCaspase proteins is denoted with stars. The numbers on the right-hand and left-hand sides are the numbers of amino acids in the JfCaspase proteins. The GenBank accession numbers of the caspase proteins from Paralichths olivaceus are ARI72010.1 (caspase 1), XP_019948600.1 (caspase 2), AFC60626.1 (caspase 3), XP_019956800.1 (caspase 6), and XP_019955218.1 (caspase 8) 
Table 3 Comparison of the amino acid sequence identities of caspase proteins in Japanese flounder Paralichthys olivaceus

\begin{tabular}{llrrrrr}
\hline caspase & \multicolumn{7}{l}{ Amino acid sequence identities (\%) } \\
\cline { 2 - 7 } & 1 & 2 & 3 & 6 & 8 & 10 \\
\hline 1 & 100 & 13 & 11 & 10 & 11 & 10 \\
2 & & 100 & 11 & 10 & 11 & 13 \\
3 & & & 100 & 21 & 13 & 11 \\
6 & & & 100 & 15 & 13 \\
8 & & & & 100 & 18 \\
10 & & & & & 100
\end{tabular}

features indicate that fish caspase proteins are structurally similar to mammalian caspase orthologs.

A BLAST search against the GenBank database revealed that the Japanese flounder caspase proteins share high sequence identity with their respective counterparts from other teleost species. Comparison of the amino acid sequences among the six Japanese flounder caspase proteins, however, revealed that they share less sequence identity (the maximum sequence identity is $21 \%$, Table 3 ), indicating that they may have different structural features. Phylogenetic analysis revealed that the selected teleost caspase proteins are clustered into three subgroups: group 1 comprises the initiator caspase 2 and caspase 8 proteins; group 2 comprises the inflammatory caspase 1 proteins; group 3 comprises the effector caspase 3 and caspase 6 proteins (Fig. 2). This finding reflects their different structural relationships.

\section{Co-expression of multiple caspase genes in Japanese flounder normal tissues and immune cells}

The expression of the JfCaspase 2, 3, 6 and 8 mRNA transcripts in the Japanese flounder normal tissues are shown in Fig. 3a. Caspase-family genes are widely distributed in various tissues of various teleost species [7, 9, 10, 13, 15]. Similarly, all four JfCaspase genes are constitutively expressed in all examined Japanese flounder tissues but at unequal expression levels. This finding, together with our previous observation that the JfCaspase 1 gene is widely present in Japanese flounder tissues [17], suggests that multiple caspase genes are required in the Japanese flounder body. However, the JfCaspase 2 gene is expressed at the highest level in the blood, followed by the skin, trunk kidney, muscle, intestine, heart, head kidney, spleen, gill and liver. The JfCaspase 3 gene is predominantly expressed in blood and skin and shows the lowest expression in the intestine and gill. The JfCaspase 6 gene is primarily expressed in the intestine, with the lowest expression in the head kidney. The JfCaspase 8 gene is highly expressed in blood but

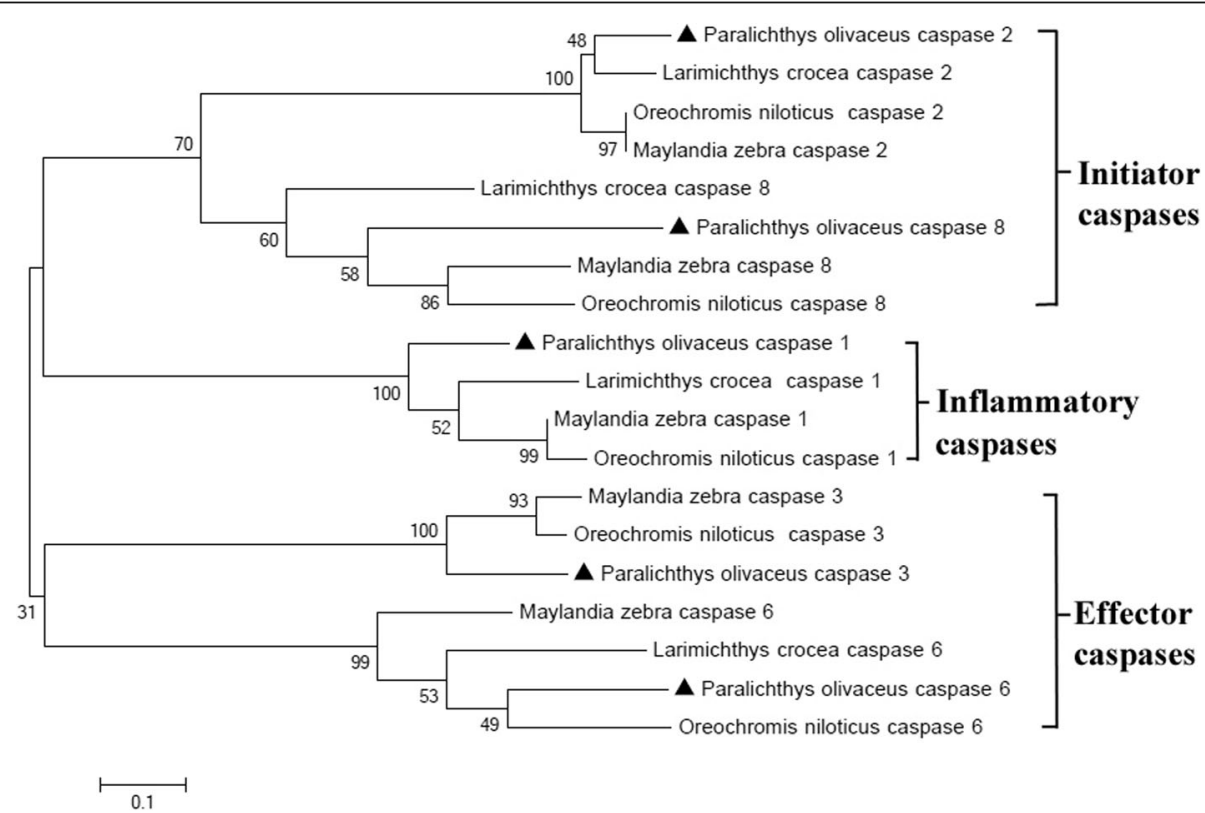

Fig. 2 Phylogenetic relationships of Japanese flounder caspase proteins. Phylogenetic relationships among the Japanese flounder caspase 1, 2, 3, 6 and 8 proteins and their counterparts in other teleost species were determined using the ClustalW program, and the bootstrap-consensus neighbor-joining phylogenetic tree was built using MEGA software version 5.0 with the default parameters. The GenBank accession numbers for the caspases proteins from the different species are as follows: Oreochromis niloticus caspase 1: XP_005459436.1, caspase 2: XP_005455468.1, caspase 3: NP_001269823.1, caspase 6: XP_013131214.1, caspase 8: XP_003457507.2; Maylandia zebra caspase 1: XP_004543706.1, caspase 2: XP_004550818.1, caspase 3: XP_004549328.1, caspase 6: XP_014268841.1, caspase 8: XP_012778477.1; Larimichthy crocea caspase 1: KKF14496.1, caspase 2: KKF24100.1, caspase 6: KKF09831.1, caspase 8: KKF31210.1; Takifugu ruubripes caspase 1R: XP_003979716.1, caspase 2R: XP_011615364.1, caspase 3: AAM43816.1, caspase 6: XP_003972493.2; Cynoglossus semilaevis caspase 6: XP_008315389.1; and those in the list in the legend of Fig. 1 

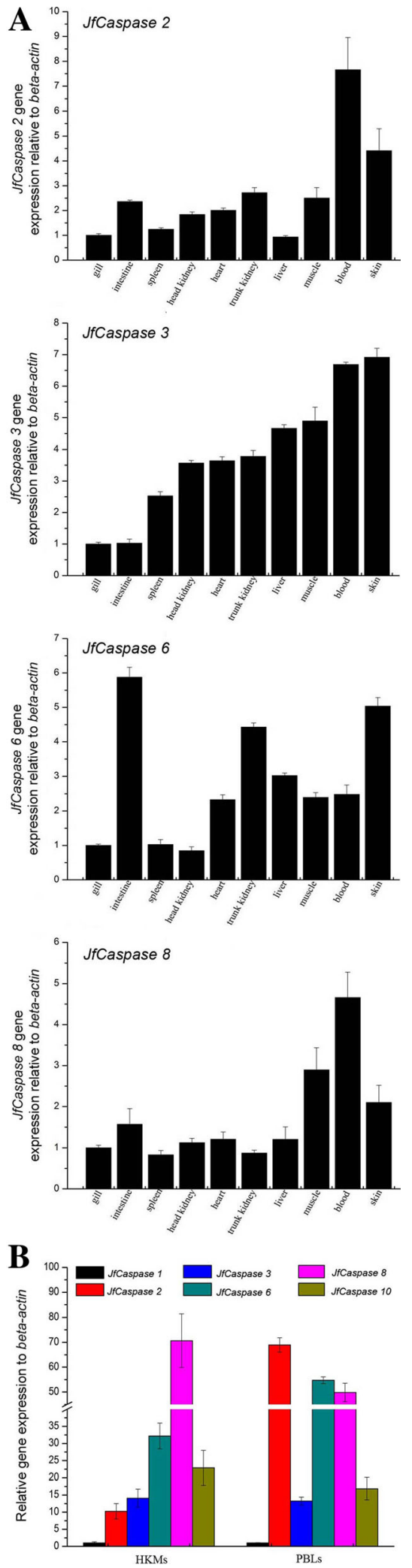

Fig. 3 Expression of JfCaspase mRNA transcripts in Japanese flounder tissues and immune cells. a qRT-PCR analysis of the relative gene expression levels of JfCaspase 1, 2, 3, 6 and 8 in Japanese flounder normal tissues. Beta-actin served as an internal reference gene. The error bars indicate the standard deviation from triplicate experiments. $\mathbf{b}$ qRT-PCR analysis of the relative gene expression levels of JfCaspase 1, 2, 3, 6, 8 and 10 in Japanese flounder head kidney macrophages (HKMs) and peripheral blood leukocytes (PBLs), with beta-actin serving as an internal control gene

is expressed at lower levels in the spleen and trunk kidney. These observations indicate that different caspase genes are constitutively but unequally expressed in Japanese flounder tissues. Similarly, the predominant expression of the caspase 2 gene in the blood of striped murrel, Channa striatus [7] and the abundant expression of the caspase 3 gene in the blood of yellow croaker, Pseudosciaena crocea [15], have been reported previously. However, the caspase 3 and 8 genes are mainly expressed in the spleen and liver, respectively, in C. striatus [7], and the caspase 2 and 3 genes are predominantly expressed in the muscle of tongue sole, Cynoglossus semilaevis [6]. These observations revealed that the dominant expression tissue of a given caspase gene varies among different teleost species, suggesting that caspase genes are diversely expressed in fish.

Next, qRT-PCR analysis was performed to compare the relative expression levels of JfCaspase genes in Japanese flounder immune cells. Figure $3 \mathrm{~b}$ showed that the basal gene expression level of JfCaspase 1 was lower than that of JfCaspase 2, 3, 6, 8 and 10 in both HKMs and PBLs. This lower expression may reflect a lower enzymatic activity of the JfCaspase 1 protein under resting conditions. The relatively higher gene expression levels of JfCaspase 2, 3, 6, 8 and 10 indicates that these genes are essential mediators of apoptosis in Japanese flounder immune cells. Alternatively, they may perform nonimmune functions under unstimulated conditions. For example, recent studies have indicated that caspase 2 activity is required for correct cell proliferation [27].

\section{Inflammatory stimulation-induced JfCaspases gene expression in Japanese flounder HKMs and PBLs}

Caspase gene expression can be significantly modulated by different inflammatory stimuli. For example, the expression of the caspase genes 1,2, 3 and 9 is modulated by bacterial infection in the tongue sole, Cynoglossus semilaevis, and has been suggested to play an essential role against bacterial infection [6]. Previous studies also reported the responses of caspase 3 and 6 proteins to viral infection in yellow-striped grunt (Haemulon flavolineatum) GF cells $[19,28]$ and the response of the caspase 8 gene to bacterial infection in sea bass, Dicentrarchus 
labrax L. [9]. We therefore examined the effect of inflammatory challenges on JfCaspase gene expression in Japanese flounder immune cells. Figure 4 shows that the gene expression of the initiator JfCaspase 2 was suppressed (by up to 0.6 -fold), while the gene expression of the initiator JfCaspase 8 were upregulated by LPS and poly(I:C) treatment (up to 2.8-fold and 2-fold higher than that of control group, respectively) in the HKMs. In addition, the gene expression of the effector IfCaspase 3 in the HKMs was only upregulated approximately 1.8 -fold at 24 and $48 \mathrm{~h}$ after LPS and poly(I:C) challenge, respectively. However, the gene expression of the effector IfCaspase 6 was upregulated until 24 and $12 \mathrm{~h}$ after LPS and poly(I:C) stimulation (by up to 2.2-fold and 3.7-fold, respectively) in the HKMs, respectively. Again, in PBLs, the gene expression of the initiator JfCaspase 2 gene expression was downregulated (up to approximately 0.2-fold lower than that of control group), while initiator JfCaspase 8 gene expression was upregulated (up to approximately 2-fold higher than that of control group) at most time points after LPS stimulation. The gene expression of the effector JfCaspase 3 was downregulated at some time points, while effector JfCaspase 6 gene expression was significantly upregulated (up to approximately 5-fold higher than that of control cells) after LPS treatment in the PBLs (Fig. 5). These opposite expression patterns suggest that a compensatory mechanism may exist, i.e., when the expression of one caspase gene was suppressed, the other caspase gene was upregulated. Interestingly, all four Japanese flounder caspase genes were upregulated upon poly(I:C) stimulation in

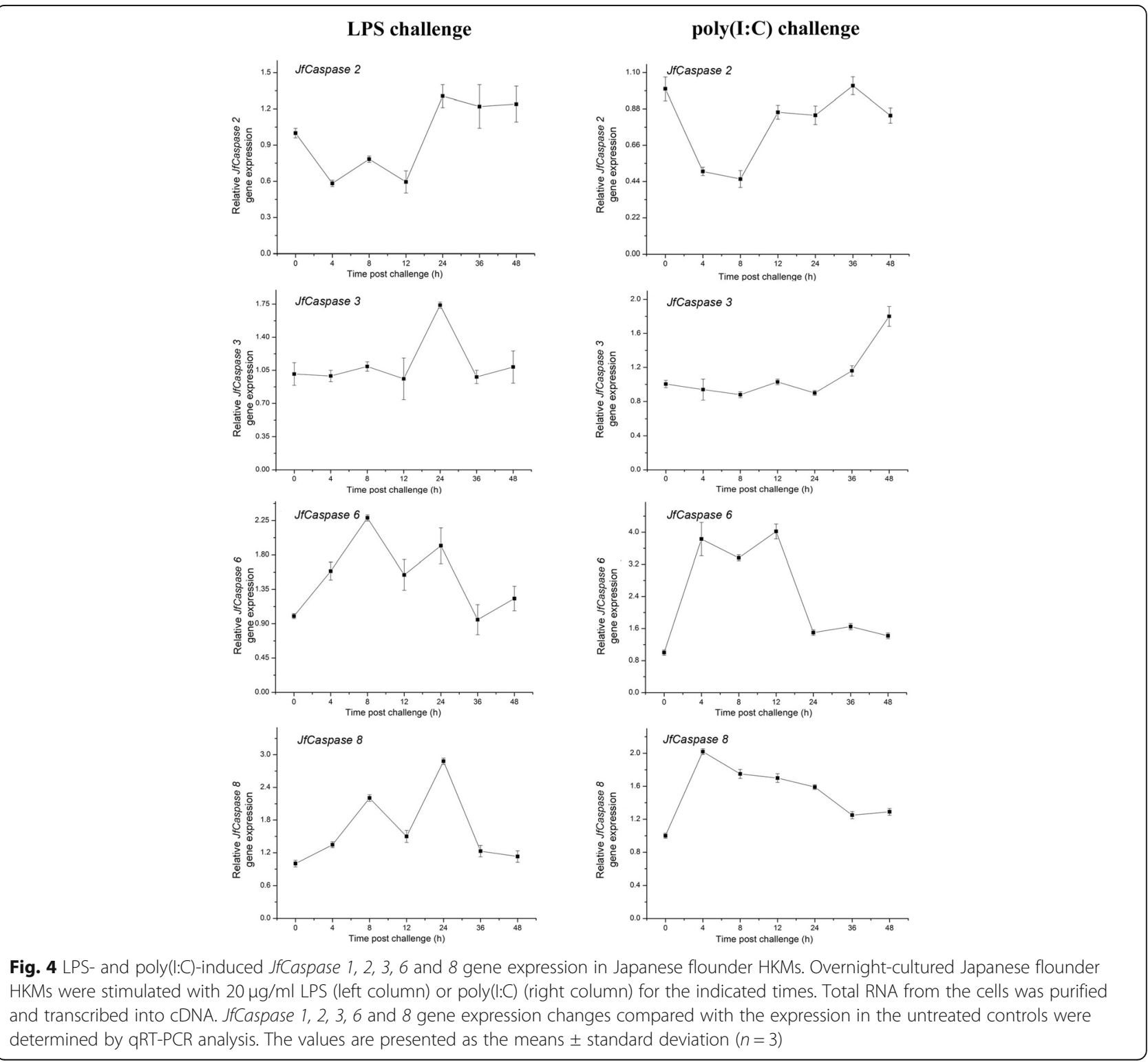


the PBLs (Fig. 5), suggesting that they may play an active role in response to viral infection. As gene expression changes may not always reflect the expression changes at the protein level, further investigations of the impact of PAMP stimulation on JfCaspase protein expression are needed. The basal gene expression levels of the JfCaspase 2, 3, 6 and 8 genes in HKMs and PBLs without PAMP challenges did not show any significant differences during the experiments (data not shown). Taken together, our findings suggest that the JfCaspase 2, 3, 6 and 8 genes may play a role in the response to bacterial and viral infections in the Japanese flounder, a hypothesis that needs to be clarified in the future.
Extracellular ATP-induced JfCaspase gene expression, enzymatic activity and apoptosis in Japanese flounder head kidney macrophages

Caspase proteins can be activated by eATP [29]. For example, the activation of the caspase proteins 3 and 8 by eATP was observed in murine macrophages [30]. We previously showed that ATP was released from fish cells into the extracellular milieu during inflammatory stimulation and infection conditions via connexin 43 and or pannexin 1 channels [31-33]. Our previous studies also demonstrated that eATP is a potent signaling molecule in the activation of Japanese flounder innate immunity [20-22]. Specially, we showed that the Japanese flounder
LPS challenge
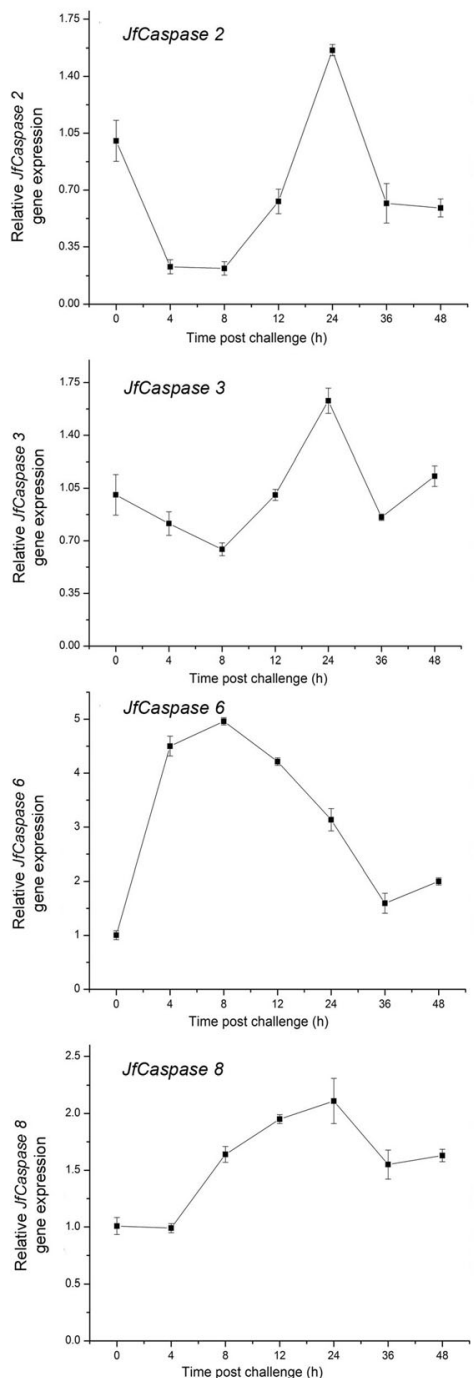

poly(I:C) challenge
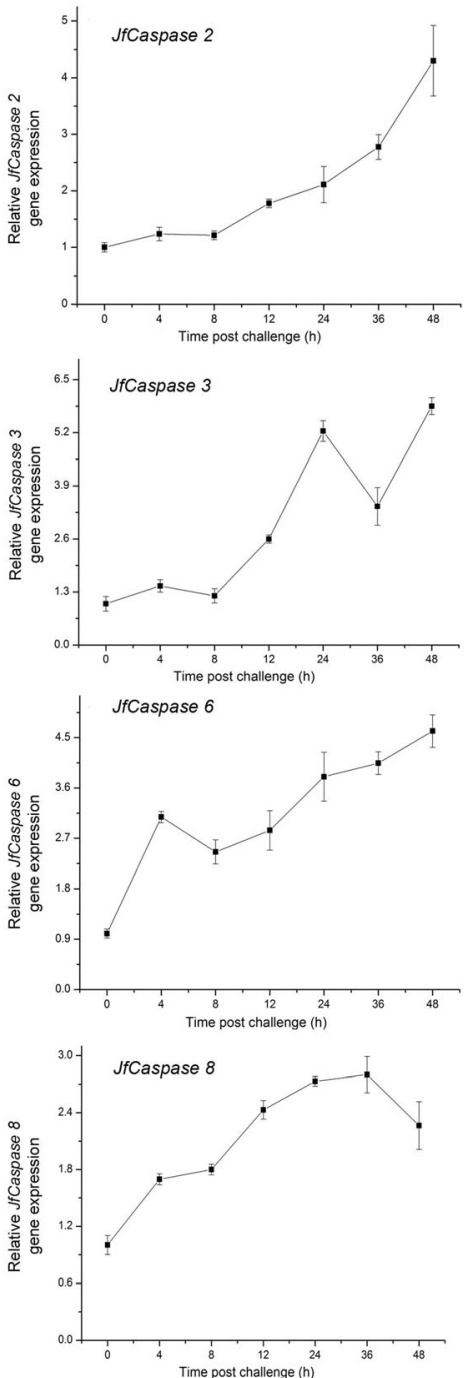

Fig. 5 LPS- and poly(l:C)-induced JfCaspase 1, 2, 3, 6 and 8 gene expression in Japanese flounder PBLs. Overnight-cultured Japanese flounder PBLs were stimulated with $20 \mathrm{\mu g} / \mathrm{ml}$ LPS (left column) or poly(l:C) (right column) for the indicated times. PAMP-induced changes in JfCaspase 1, 2, 3, 6 and 8 gene expression were determined by qRT-PCR analysis. The values are presented as the means \pm standard deviation $(n=3)$ 
ATP-gated P2X7 receptor has an estimated $\mathrm{EC}_{50}$ of 743 $\pm 299 \mu \mathrm{M}$ for ATP [20], and $1 \mathrm{mM}$ ATP treatment can result in profound up-regulation of pro-inflammatory cytokine gene expression, iNOS activity and inflammatory mediators production, including ROS and NO, in Japanese flounder HKMs [22]. Recently, we found that eATP modulates IfCaspase 1 gene expression and enzymatic activity in Japanese flounder immune cells [17]. To examine whether eATP stimulation can affect the expression of other caspase genes, the Japanese flounder HKMs were treated with $1 \mathrm{mM}$ ATP, and the resultant gene expression changes are shown in Fig. 6a. Similar to IfCaspase 1, the IfCaspase 2, 3, 6 and 8 genes were upregulated following ATP treatment although they exhibited different response patterns. Without ATP treatment, the basal gene expression level of JfCaspase 2, 3, 6 and 8 did not show any significant differences during the experiments (data not shown). We next examined the enzymatic activity changes following eATP treatment. As shown in Fig. 6b, eATP treatment broadly upregulated the enzymatic activity of all the JfCaspase proteins in the HKMs. Specifically, the enzymatic activity of the JfCaspase 2 and 3 proteins was increased $12 \mathrm{~h}$ after ATP stimulation, while the increased enzymatic activity of the JfCaspase 6 and 8 proteins was observed 24 $h$ after ATP treatment. The enhanced JfCaspase activity may reflect increased apoptosis activity in the HKMs. To test this hypothesis, we performed a DNA fragmentation

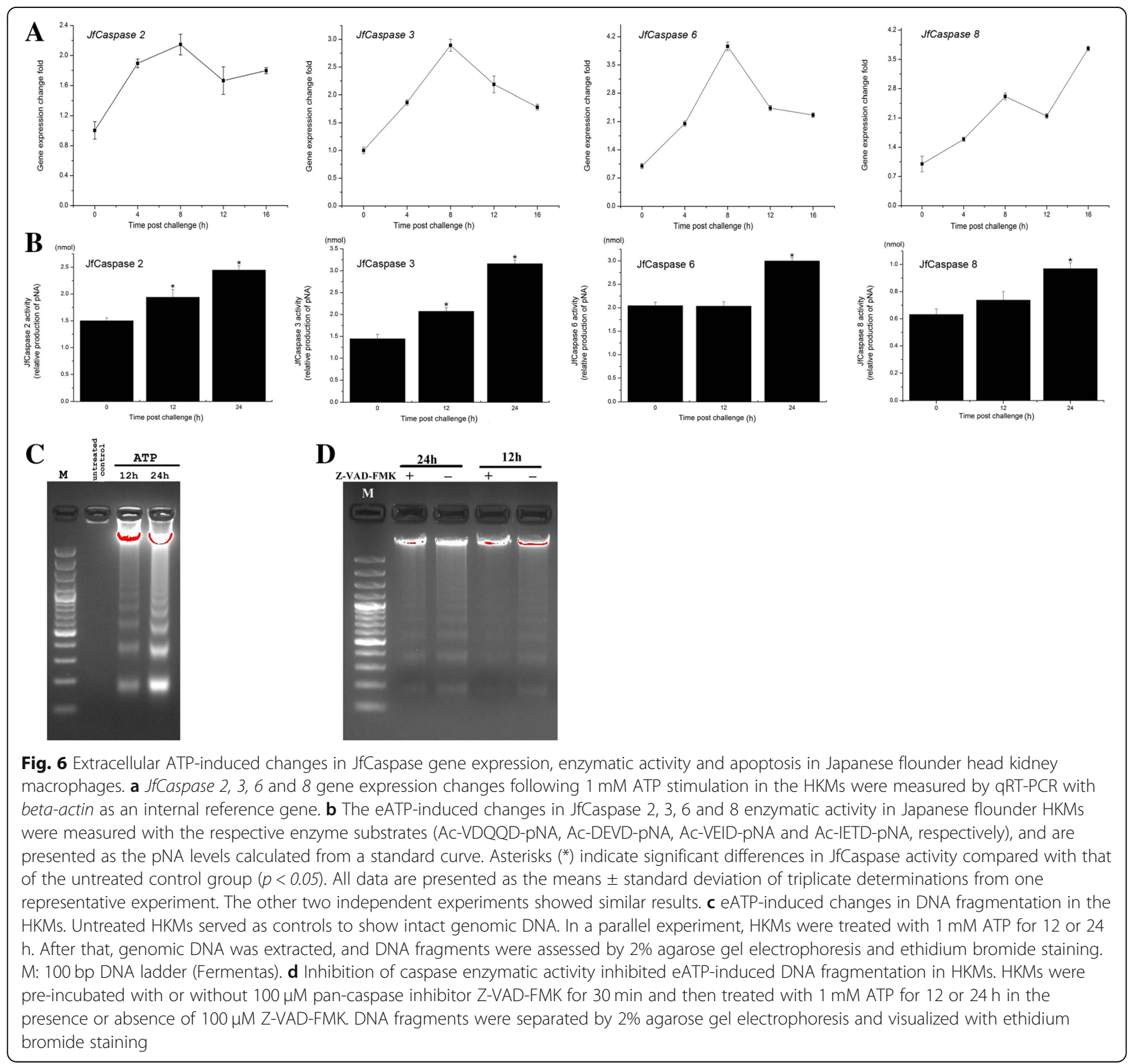


assay. As shown in Fig. 6c, DNA fragmentation was observed following eATP treatment in the HKMs. However, this eATP-induced DNA fragmentation was inhibited by pre-incubation with the pan-caspase inhibitor Z-VAD-FMK (Fig. 6d). Previous studies have revealed that the caspase 3, 6 and 8 genes play important roles in apoptotic signal pathway in fish $[9,10,13,15$, $18,34,35]$. As eATP-induced apoptosis was reported to be mediated by activation of the Caspase 1,3 and 8 proteins in murine macrophages $[29,30]$, the above observations thus highlight the important role of eATP in the induction of apoptosis through increases in the gene expression and enzymatic activity of multiple caspase protein family members expressed in Japanese flounder immune cells. Future studies are needed with specific inhibitors to inhibit the enzymatic activity of individual caspase proteins and determine the contributions of the individual caspase proteins to eATP-induced apoptosis in the HKMs.

\section{Conclusions}

Our findings revealed the different responses of different caspase genes to inflammatory and eATP stimulation in Japanese flounder immune cells and provided new evidence for the involvement of caspase protein(s) in eATP-induced apoptosis in fish.

\section{Abbreviations}

ATP: Adenosine triphosphate; CARD: Caspase recruitment domain; CASc: Caspase, interleukin-1 beta converting enzyme (ICE) homologues; DED: Death effector domain; eATP: Extracellular ATP; HKM: Head kidney macrophage; JfCaspase: Japanese flounder caspase; LPS: Lipopolysaccharides; PBL: Peripheral blood leukocyte; pNA: p-nitroaniline; poly(l:C): Polyinosinicpolycytidylic acid

\section{Acknowledgements}

None.

\section{Funding}

This study was finically supported by the National Natural Science Foundation of China (grant No. 31572645), the Natural Science Foundation of Tianjin (grant No. 18JCZDJC33600), the University Yong Talent Cultivation Program provided by Tianjin Municipal Education Commission, the Science Promotion Program for Young Scholars provided by Tianjin Normal University (grant No. 52XC1503), the Tianjin Development Program for Innovation and Entrepreneurship and the Innovation Team of Tianjin Fisheries Research System (grant NO. ITTFRS2017007). The funders had no role in study design, data collection and analysis, decision to publish, or preparation of the manuscript.

\section{Availability of data and materials}

The datasets used and/or analyzed during the current study are available from the corresponding author on reasonable request.

\section{Authors' contributions}

Conceived and designed the experiments: SL JS. Performed the experiments: JL WP GH. Analyzed the data: SL JL WP GH. Contributed reagents/materials/ analysis tools: SL JS. Wrote the paper: SL. All authors read and approved the final manuscript.

\section{Ethics approval and consent to participate}

All experiments were conducted in accordance with the $\mathrm{NIH}$ guidelines for the care and use of experimental animals and these studies were approved by the animal care and use committee of the College of Life Sciences, Tianjin Normal University (\#2018-01).

Consent for publication

Not applicable.

Competing interests

The authors declare that they have no competing interests.

\section{Publisher's Note}

Springer Nature remains neutral with regard to jurisdictional claims in published maps and institutional affiliations.

Received: 5 February 2018 Accepted: 26 December 2018

Published online: 08 January 2019

\section{References}

1. Mcllwain DR, Berger T, Mak TW. Caspase Functions in Cell Death and Disease. Cold Spring Harb Perspect Biol. 2013;5(4):a008656.

2. Jorgensen I, Miao EA. Pyroptotic cell death defends against intracellular pathogens. Immunol Rev. 2015;265(1):130-42.

3. Lamkanfi M, Declercq W, Kalai M, Saelens X, Vandenabeele P. Alice in caspase land. A phylogenetic analysis of caspases from worm to man. Cell Death Differ. 2002;9(4):358-61.

4. Boatright KM, Salvesen GS. Mechanisms of caspase activation. Curr Opin Cell Biol. 2003;15(6):725-31.

5. López-Castejón G, Sepulcre MP, Mulero I, Pelegrín P, Meseguer J, Mulero V. Molecular and functional characterization of gilthead seabream Sparus aurata caspase-1: the first identification of an inflammatory caspase in fish. Mol Immunol. 2008:45(1):49-57.

6. Long $H$, Sun L. Molecular characterization reveals involvement of four caspases in the antibacterial immunity of tonque sole (Cynoglossus semilaevis). Fish Shellfish Immunol. 2016;57:340-9.

7. Kumaresan V, Ravichandran G, Nizam F, Dhayanithi NB, Arasu MV, Al-Dhabi NA, Harikrishnan R, Arockiaraj J. Multifunctional murrel caspase 1, 2, 3, 8 and 9: conservation, uniqueness and their pathogen-induced expression pattern. Fish Shellfish Immunol. 2016;49:493-504.

8. Arockiaraj J, Gnanam AJ, Muthukrishnan D, Pasupuleti M, Milton J, Singh A. An upstream initiator caspase 10 of snakehead murrel Channa striatus, containing DED, p20 and p10 subunits: molecular cloning, gene expression and proteolytic activity. Fish Shellfish Immunol. 2013;34(2):505-13.

9. Reis MIR, Costa-Ramos C, do Vale A, dos Santos NMS. Molecular cloning of sea bass (Dicentrarchus labrax L.) caspase- 8 gene and its involvement in Photobacterium damselae ssp. piscicida triggered apoptosis. Fish Shellfish Immunol. 2010;29(1):58-65.

10. Reis MIR, Nascimento DS, do vale A, Silva MT, dos Santos NMS. Molecular cloning and characterisation of sea bass (Dicentrarchus labrax L.) caspase-3 gene. Mol Immunol. 2007;44(5):774-83.

11. Reis MIR, do Vale A, Pinto C, Nascimento DS, Costa-Ramos C, Silva DSP, Silva MT, dos Santos NMS. First molecular cloning and characterisation of caspase-9 gene in fish and its involvement in a gram negative septicaemia. Mol Immunol. 2007:44(7):1754-64.

12. Elvitigala DAS, Whang I, Premachandra HKA, Umasuthan N, Oh M-J, Jung S-J, Yeo S-Y, Lim B-S, Lee J-H, Park H-C, et al. Caspase 3 from rock bream (Oplegnathus fasciatus): genomic characterization and transcriptional profiling upon bacterial and viral inductions. Fish Shellfish Immunol. 2012;33(1):99-110.

13. Laing KJ, Holland J, Bonilla S, Cunningham C, Secombes CJ. Cloning and sequencing of caspase 6 in rainbow trout, Oncorhynchus mykiss, and analysis of its expression under conditions known to induce apoptosis. Dev Comp Immunol. 2001;25(4):303-12.

14. Mu Y, Xiao X, Zhang J, Ao J, Chen X. Molecular cloning and functional characterization of caspase 9 in large yellow croaker (Pseudosciaena crocea). Dev Comp Immunol. 2010;34(3):300-7.

15. Li M, Ding Y, Mu Y, Ao J, Chen X. Molecular cloning and characterization of caspase-3 in large yellow croaker (Pseudosciaena crocea). Fish Shellfish Immunol. 2011;30(3):910-6.

16. Kurobe T, Hirono I, Kondo H, Yamashita M, Aoki T. Molecular cloning, expression, and functional analysis of caspase-10 from Japanese flounder Paralichthys olivaceus. Fish Shellfish Immunol. 2007;23(6):1266-74. 
17. Li S, Peng W, Li J, Hao G, Geng X, Sun J. Characterization of Japanese flounder (Paralichthys olivaceus) Caspase1 involved in extracellular ATPmediated immune signaling in fish. Fish Shellfish Immunol. 2017;67:536-45.

18. Banerjee C, Goswami R, Verma G, Datta M, Mazumder S. Aeromonas hydrophila induced head kidney macrophage apoptosis in Clarias batrachus involves the activation of calpain and is caspase-3 mediated. Dev Comp Immunol. 2012;37(3):323-33.

19. Imajoh M, Sugiura H, Oshima S-I. Morphological changes contribute to apoptotic cell death and are affected by caspase-3 and caspase-6 inhibitors during red sea bream iridovirus permissive replication. Virology. 2004;322(2): 220-30.

20. Li S, Li X, Coddou C, Geng X, Wei J, Sun J. Molecular characterization and expression analysis of ATP-gated P2X7 receptor involved in Japanese flounder (<italic>Paralichthys olivaceus</italic $>$ ) innate immune response. PLoS One. 2014;9(5):e96625.

21. Li S, Chen X, Hao G, Geng X, Zhan W, Sun J. Identification and characterization of a novel NOD-like receptor family CARD domain containing 3 gene in response to extracellular ATP stimulation and its role in regulating LPS-induced innate immune response in Japanese flounder (Paralichthys olivaceus) head kidney macrophages. Fish Shellfish Immunol. 2016;50:79-90

22. Li S, Chen X, Li J, Li X, Zhang T, Hao G, Sun J. Extracellular ATP is a potent signaling molecule in the activation of the Japanese flounder (Paralichthys olivaceus) innate immune responses. Innate Immunity. 2018; In press.

23. Li S, Li X, Gen X, Chen Y, Wei J, Sun J. Identification and characterization of lipopolysaccharide-induced TNF-alpha factor gene from Japanese flounder Paralichthys olivaceus. Vet Immunol Immunopathol. 2014;157(3-4):182-9.

24. Li S, Li J, Wang N, Hao G, Sun J. Characterization of UDP-activated purinergic receptor P2Y6 involved in Japanese flounder Paralichthys olivaceus innate immunity. Int J Mol Sci. 2018;19(7):2095.

25. Li S, Chen X, Geng X, Zhan W, Sun J. Identification and expression analysis of nascent polypeptide-associated complex alpha gene in response to immune challenges in Japanese flounder Paralichthys olivaceus. Fish Shellfish Immunol. 2015;46(2):261-7.

26. Cohen GM. Caspases: the executioners of apoptosis. Biochem J. 1997;326(1): $1-16$.

27. Forsberg J, Zhivotovsky B, Olsson M. Caspase-2: an orphan enzyme out of the shadows. Oncogene. 2017;36:5441-4.

28. Miwa S, Mano N, Aranishi F. Detection of caspase activities in cultured fish cells infected with viral deformity virus. Fish Pathol. 2002;37(1):35-7.

29. Ferrari D, Los M, Bauer MK, Vandenabeele P, Wesselborg S, Schulze-Osthoff K. P2Z purinoreceptor ligation induces activation of caspases with distinct roles in apoptotic and necrotic alterations of cell death. FEBS Lett. 1999; 447(1):71-5.

30. Noguchi T, Ishii K, Fukutomi H, Naguro I, Matsuzawa A, Takeda K, Ichijo H. Requirement of reactive oxygen species-dependent activation of ASK1-p38 MAPK pathway for extracellular ATP-induced apoptosis in macrophage. J Biol Chem. 2008;283(12):7657-65.

31. Li S, Peng W, Chen X, Geng X, Zhan W, Sun J. Expression and role of gap junction protein connexin43 in immune challenge-induced extracellular ATP release in Japanese flounder (Paralichthys olivaceus). Fish Shellfish Immunol. 2016;55:348-57.

32. Li S, Li J, Wang N, Zhang T, Xu Y, Sun J. Expression analysis of Pannexin 1 channel gene in response to immune challenges and its role in infectioninduced ATP release in tilapia (Oreochromis niloticus). Fish Shellfish Immunol. 2018;81:470-5.

33. Li S, Li X, Chen X, Geng X, Sun J. ATP release channel Pannexin1 is a novel immune response gene in Japanese flounder Paralichthys olivaceus. Fish Shellfish Immunol. 2014;40(1):164-73.

34. Sakata S, Yan Y, Satou Y, Momoi A, Ngo-Hazelett P, Nozaki M, Furutani-Seiki M, Postlethwait J, Yonehara S, Sakamaki K. Conserved function of caspase-8 in apoptosis during bony fish evolution. Gene. 2007;396(1):134-48.

35. Yabu T, Kishi S, Okazaki T, Yamashita M. Characterization of zebrafish caspase-3 and induction of apoptosis through ceramide generation in fish fathead minnow tailbud cells and zebrafish embryo. Biochem J. 2001;360(1): $39-47$.

\section{Ready to submit your research? Choose BMC and benefit from:}

- fast, convenient online submission

- thorough peer review by experienced researchers in your field

- rapid publication on acceptance

- support for research data, including large and complex data types

- gold Open Access which fosters wider collaboration and increased citations

- maximum visibility for your research: over $100 \mathrm{M}$ website views per year

At BMC, research is always in progress.

Learn more biomedcentral.com/submissions 